\title{
DISTRIBUTION OF MARINE DEBRIS STRANDED ON A CITY BEACH: A CASE STUDY OF LAS CANTERAS BEACH, GRAN CANARIA
}

\author{
LYDIA MCKNIGHT $^{1}$ \& GERMÁN RODRÍGUEZ ${ }^{1,2}$ \\ ${ }^{1}$ Departamento de Física, Universidad de Las Palmas de Gran Canaria, Spain \\ ${ }^{2}$ Applied Marine Physics and Remote Sensing Group, Environmental Research and Natural Resources Institute \\ (i-UNAT), Universidad de Las Palmas de Gran Canaria, Spain
}

\begin{abstract}
An approach to the spatial and temporal distribution of marine debris stranded on Las Canteras Beach is developed by means of surveys carried out during one year, along three transects located on the southern, northern, and central parts of the beach. Results evidence that debris stranded on the beach represent an almost permanent type of pollution, but with a large time variability in the number of items observed along the three transects, as well as in the type and origin of the debris collected at the different stretches of the beach.
\end{abstract}

Keywords: marine debris, beach management, Las Canteras Beach.

\section{INTRODUCTION}

Plastic products predominate in daily life materials due to their durability and lightweight characteristics. However, these same characteristics make plastics a threat to ecosystems when inadequately disposed of, due to their persistence in terrestrial, aquatic, and marine environments [1], [2]. In particular, when these materials reach coastal areas it may have negative visual impacts on coastal human communities, as well as indirect effects, such as loss of tourism revenue and recreation value, clean-ups costs, and many others [3]-[5].

Plastic items are the main component of marine debris [6], [7], defined as "any manufactured or processed solid waste material that enters the marine environment from any source" [8], and social awareness of the impacts of this kind of pollution in coastal regions, as well as in open ocean, is increasing [2], [6], [9].

The sources of marine debris are extensive and can be ocean- or land-based [8], [10]. Ocean-based debris are materials either intentionally or accidentally dumped or lost overboard from vessels [2], [11]. In contrast, land-based debris generally originate from urban and industrial waste sites, sewage and storm-water outfalls, and terrestrial litter that reaches the waterways systems, or even directly left by beach users [11], [12]. Population size, mainly settled in coastal regions, and the quality of the waste management systems determine the amount of land-based plastic debris entering in the ocean [13]. Once the debris enters the marine environment, they can be transported elsewhere [2] through a combination of wind and current patterns, sink [10], or deposited at coasts, mainly by the action of tides, waves, and the local effects imposed by topographic conditions [14], [15].

The knowledge on the behaviour of this kind of pollution is still poor. The complexity of the physical processes involved in its transport, deposition, and degradation rate, as well as the different type of sources, makes the development of models to predict its behaviour a challenging task. Furthermore, the large local variability of these aspects implies the need of studies at each specific area to gain insight into the issue in that particular location.

Las Canteras Beach is considered to be one of the few globally city beaches visited throughout the year. It has a large socioeconomic importance for the city of Las Palmas de Gran Canaria and constitute a unique ecosystem, with different habitats of national and 
international interest. So, it has been declared as Special Conservation Zone (ZEC) and Site of Community Importance (LIC). Due to its natural characteristics, Las Canteras Beach represents a natural landscape significantly vulnerable to the arrival of marine debris. Hence, it is important to optimise the efficiency of management plans for this kind of pollution, as well as improve the benefits and efficiency of beach clean ups as a mitigation tool. This requires improving our understanding of transport mechanisms and the identification of sources and sinks, starting with the development of field surveys [10], [16], [17].

The present work aims to characterize the spatial and temporal distribution of marine debris on Las Canteras Beach, by means of one-year survey at three different transects. The main goal of this initial study is to establish a baseline for future actions, including the development of environmental management plans, and help to identify the different possible marine debris sources affecting the area.

\section{STUDY ZONE}

The Canary Islands Archipelago is located between $29^{\circ} 15^{\prime} \mathrm{N}-27^{\circ} 10^{\prime} \mathrm{N}$ and $19^{\circ} 00^{\prime} \mathrm{W}-$ $12^{\circ} 45^{\prime} \mathrm{W}$, in front of the north-west African coast and it is formed by seven main islands (from east to west): Lanzarote, Fuerteventura, Gran Canaria, Tenerife, La Gomera, La Palma, and El Hierro (Fig. 1). The islands are strongly affected by the prevailing northeastern winds, also known as trade winds, and by the Canary current, a ramification of the southern flux of the Gulf's Current, heading south.

Las Canteras Beach is located at the north-eastern coast of the Gran Canaria Island (Fig. 1), and orientated towards the northwest (NW) within the Confital Bay, which is sheltered from the prevailing north-eastern winds by La Isleta headland. The beach is a $3 \mathrm{~km}$ long fine-

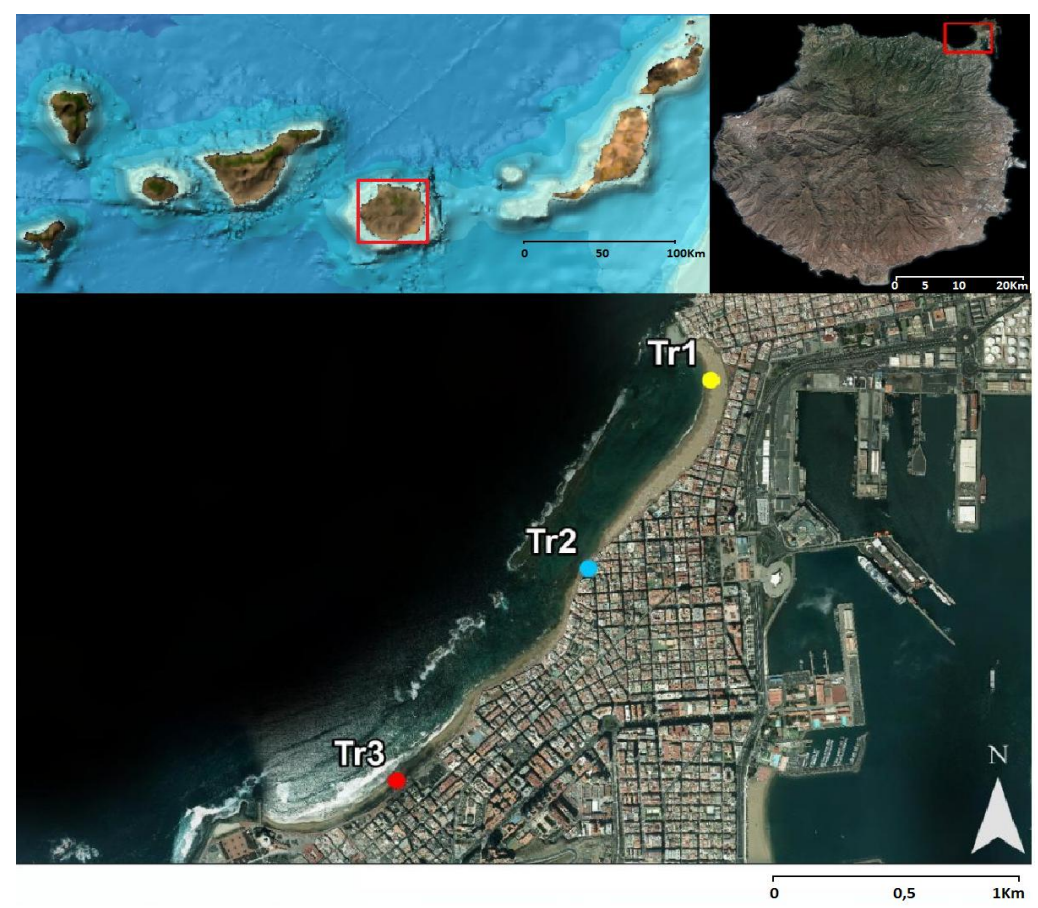

Figure 1: Canary Islands Archipelago (top left), Gran Canaria Island (top right), and aerial view of Las Canteras Beach with their sample transects locations (bottom). 
grain blonde sand beach, providing recreational opportunities to citizens of Las Palmas de Gran Canaria, the largest and most heavily populated city in the Canary Islands. It is bound to the north by La Isleta and southward by a groyne, and exhibits the particular geomorphological characteristic of being semi-enclosed by a discontinuous natural rocky reef running parallel to the coast and separated about $200 \mathrm{~m}$ from the shoreline [18]. This morphological characteristic enables several different beach environments and uses, mainly because some parts are well exposed to wave action while other are partially or totally sheltered, depending on wave direction approach and tidal conditions. The aerial image of the study area (Fig. 1) reveals that the southern section of the beach is totally free from the barrier protection. In the central area of the beach, known as "Peña La Vieja", the barrier is interrupted forming two channels which allows wave propagation toward the beach, as well as current flow. From this point to almost the end of northern part of the beach, "La Puntilla" area, it is uninterrupted but another discontinuity is present at the very end of the beach.

\section{METHODOLOGY FOR MARINE DEBRIS SAMPLING AND PROCESSING}

Due to the wide range of sizes [1] and types of marine debris found in beach surveys, many different monitoring methodologies have been suggested [19]. Nevertheless, it is obvious that the best methodology is one that adjusts to the main goal of study. In this respect, given that the detection of the areas where marine debris tend to deposit and the identification of its possible sources are among the objectives of the study, it is interesting to collect only the debris recently left by the sea, also known as "fresh debris" [17], [20], [21], and not the items left behind by beach users, or left by the sea a long time ago, which would make more difficult these tasks. In addition, different management actions are occurring on the study area, as is the case of the cleaning services efforts, which could seriously interfere with the sampling procedure if not taken into account. Nevertheless, cleaning timetables and procedures have been properly foreseen, thus minimizing its effects on the field work. The marine debris sampling period cover more than one year, from November 2014 until March 2016, although only the last seven surveys have been considered, due to adjustments on the used methodology. The sampling interval has been bi-monthly, and the selection of the sampling dates carefully determined by taking into account different factors. Thus, campaigns have been synchronized with tidal phases, carrying out the samples collection during low spring tides to maximize the intertidal exposure. Additionally, samplings have not been carried out during weekends to avoid large quantities of debris left by users. Although cleaning services operate during late afternoons and night, there is a possibility that locally abnormal amounts of debris could not be totally removed. So, avoiding these days of higher densities of beach visitors is considered as a safe bet. To summarize, sampling periods have been chosen to coincide with working days, low spring tides, provided that cleaning services had not operated in the period between the low tide and the previous high tide. Naturally, all these restrictions reduce the available time windows for debris collection.

The sampling transects selection have been based on the idea of having a representation of the main environments naturally present on the beach, time limitation for debris collections, and sand availability throughout the year. Beach sections where high tide reaches the promenade wall where not chosen because it could influence debris deposition [20]. With the above considerations in mind, three transects were chosen for monitoring marine debris deposition: La Puntilla (TR1), Playa Chica (TR2), and La Cicer (TR3) (Fig. 1).

The TR1 (La Puntilla), northern end, represents a semi-closed environment and it is also the most sheltered place from the prevailing north-eastern winds, located on the proximity of a shelter area for small fisherman's boats. Transect TR2 (Playa Chica) is also a semi-enclosed beach environment but with a steeper beach face and pocket beach morphology due to the 
course of the walkway. The last transect considered, TR3 (La Cicer), is on the southern limit of Las Canteras Beach and it is exposed to the wave action. The sedimentary characteristics in this transect differs from the other two in seasonal sedimentary transport, grain size and composition terms [18].

The monitoring plan carried out during the present study includes two different sampling methodologies, depending on the debris diameter. The diameter thresholds have been established on the basis of the cleaning squad capacity, which usually collects debris ranging from cigarette filters to bigger items, whereas smaller pieces are less likely left by beach users and are not targeted by most clean-up efforts [10]. The debris groups established in terms of the diameter thresholds set are micro- $(<5 \mathrm{~mm})$, meso- $(5-25 \mathrm{~mm})$, and macro-debris $(>25$ $\mathrm{mm})$.

\subsection{Micro and meso-debris sampling and processing}

The sampling methodology used to monitor micro and meso-debris has been selected looking for a balance between time consumption during the sampling process and effective extraction of the desire materials sizes and types. Thus, the minimum size considered is about $1 \mathrm{~mm}$, so plastic materials with diameter in the range $1-25 \mathrm{~mm}$ have been included in this category.

Each sampling transect is $50 \mathrm{~m}$ length along the upper high tide water mark. The transect position is repeated for each sampling date throughout the year. The high tide line was selected because it holds much more plastic left by the receding tide than other areas of the intertidal zone [7], [19]. The minimum width of the transect recommended in the literature [10] has been used, that is, a total of six $0.25 \mathrm{~m}^{2}(50 \mathrm{~cm} \times 50 \mathrm{~cm})$ quadrants of surface sediment evenly distributed $10 \mathrm{~m}$ apart, such as the depicted in Fig. 2. For each quadrant, sediment has been collected from a depth of no more than $1 \mathrm{~cm}$, approximately, until a recipient of 1 litre was filled from the uppermost sand layer, so including the materials most recently deposited by the tide. The total of the six surface volume buckets corresponding to each transect was deposited in a $20 \mathrm{~L}$ tub previously filled with clean filtered seawater. The plastic fragments in the sample floated on the water surface, enabling their separation from the rest of the sampled materials and to remove them from the tub manually with a skimmer. This procedure was adapted from [19] and has been also used in [20], but with different sediment volumes.

The procedure used after collecting the debris samples includes density separation, filtration, sieving, and visual sorting of micro-plastics, such as illustrated in Fig. 3. Only the

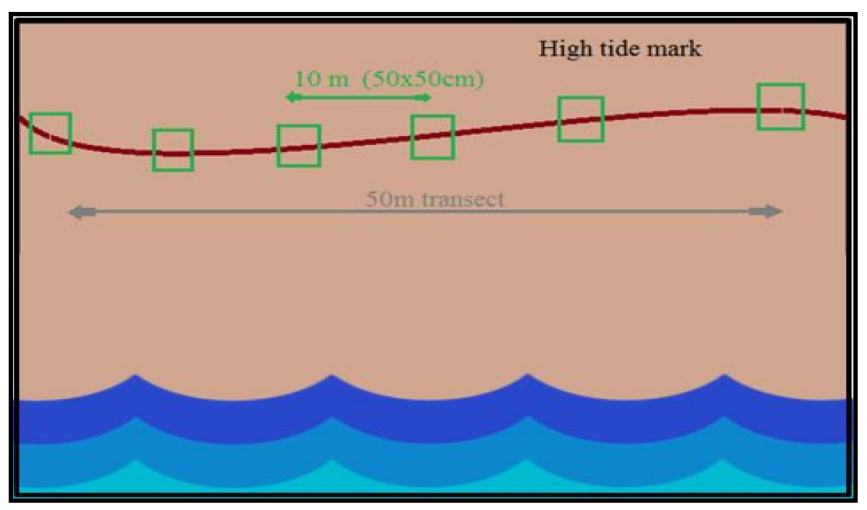

Figure 2: Micro- and meso-debris sampling transect illustration. 
two first steps were carried out in situ, due to the facility to transport the materials after density separation. Before the sieving, samples were left drying under normal temperature conditions in a ventilated room, protected from the direct sunlight and abrupt changes of temperature, and any organic material was separated from the plastic. Through the sieving process, the particles were separated into four groups of size by passing them through a sieve cascade of different mesh size ranges, enabling to classify debris into four main groups: $<1.4$ $\mathrm{mm}, 1.4-4 \mathrm{~mm}, 4-9 \mathrm{~mm}, 9-25 \mathrm{~mm}$.

For each size range, plastics were grouped into various categories: film, line, pellet, fragment or hard pieces, foam pieces [7]. This process has been carried out by carefully naked eye visual sorting and with help of magnifying glass for smaller pieces, mainly for the items that passed the smaller mesh size in the sieve $(1.4 \mathrm{~mm})$. Thus, items with diameter over $1 \mathrm{~mm}$, approximately, have been considered. Materials corresponding to each size and type group were counted and weighted on a balance accurate to $0.1 \mathrm{mg}$.

\subsection{Macro-debris sampling and processing}

The method applied for sampling macro-debris ( $>25 \mathrm{~mm}$, approximately the size of cigarette filters) is an adaptation of the "Top bottom and vegetation lines" methodology [17], collecting, during the low tide, only "fresh debris", or recently debris deposited by the last tide. Higher strandlines tend to accumulate or present higher quantities of debris. Contrarily, the lower wet strandlines usually have only small amounts of litter, thereby spatial averages in these areas result in lower figures, but it is necessary to avoid overestimation of debris concentrations. Some modifications were made to the original sampling procedure to adapt it to the main goals of the study. These modifications are related to transect length and sampling only upper and lower strandlines (or tide water marks), because vegetation line is only used when long-term accumulation debris is wanted. The original length established according to the bibliography $100 \mathrm{~m}$, was not adequate due to time unavailability, lack of beach length and/or sedimentary materials along two of the transects (Playa Chica and La Cicer transects). Consequently, a reduction to $50 \mathrm{~m}$ length and $1 \mathrm{~m}$ of width, for both lower and upper strandlines, was done per transect, as illustrated in Fig. 4. The beach area covered is by using these values is $100 \mathrm{~m}^{2}$ and the transect position was the same for each sampling date.

Material belonging to this type was simultaneously collected with the meso- and microdebris sampling, due to their upper strandline coincidence. All the collected debris was firstly rinsed off with water and left drying under normal temperature conditions, in a ventilated and protected from the direct sunlight effect room. Once debris was dried, the collected items were sorted and classified according to the following general categories: plastic, rubber, processed lumber, clothing/fabric, paper/cardboard, and metal [3], [21], [22] but with some

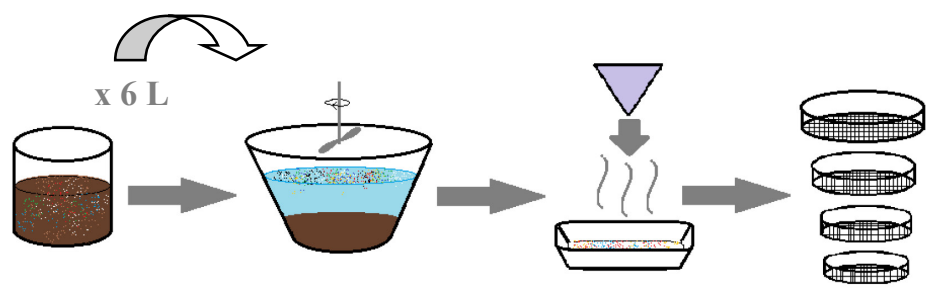

Figure 3: Schematic micro- and meso-debris sampling procedure. 


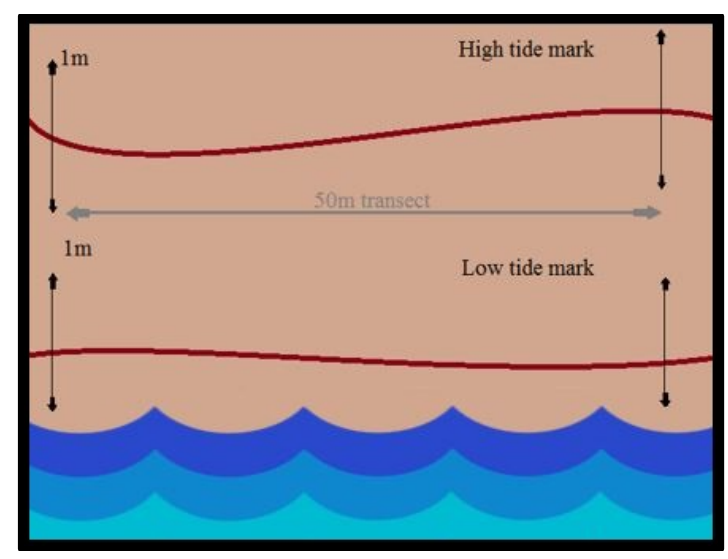

Figure 4: "Top and bottom line" methodology.

small modifications. Cigarette butts were considered separately because of their predominant occurrence in comparison with the rests of the groups. Main groups were further broken down subcategories, giving more attention to synthetic materials. Items from each category were counted and weighted on a balance accurate to $0.01 \mathrm{gr}$.

An attempt for identifying the main use or activity related with the collected materials before entering the waterways, known as activities related debris [2], [3], [17], [23], [24], has been has been done when possible. This identification can only be applied on limited items and could lead to a possible disposal source. This classification method has been taken with caution in the present study because of the great source of uncertainty which some items could cause. A list of some typical items considered as marine sources debris and others whose source is unknown is given in Table 1 .

Items brought by the sea and without a clear marine-related activity relationship have been explored in depth, looking for possible signs or marks on the material's surface (see Fig. 5), for trying to assign some origin source. In this sense, signs such as high degradation, biofouling or bites marks on the surface could help to assign the item a marine origin, or at least marine transport and not locally disposed, with a significant confidence [4], [21]. Those items with any of the cited signs detected, or which could not be related to marine activities, were considered as unknown source because it could equally come from marine source (but stayed in the marine environment for a very short period of time) or locally disposed. Thanks to the cleaning efforts and very little amount of beach users during the time of beach surveys, the locally disposal debris possibility can be considered low, but not null, and degradation signs method is appropriate because no item is left at the beach for a long period of time.

\section{RESULTS AND DISCUSSION}

\subsection{Micro-meso debris}

The number of items per square meter found on each transect, during the seven surveys carried out during the sampling period (March 2015-March 2016), is presented in Fig. 6. The sampling period covers only one year and, consequently, it is not possible to examine the average evolution of this parameter throughout the year. The available information reveals that there is no a simple pattern during the sampling period. Thus, the number of items 
Table 1: List of some items of debris with marine-related (blue), and unknown source (grey).

\begin{tabular}{|cc|}
\hline Marine source & Unknown source \\
\hline Nylon rope/net fragments & Beverage bottles \\
Buoys/floats & Plastic bags \\
\hline Fishing lures/line & Bottles and containers caps/lids \\
Light sticks & Balloons \\
Packaging bands & Cigarette filters \\
\hline
\end{tabular}
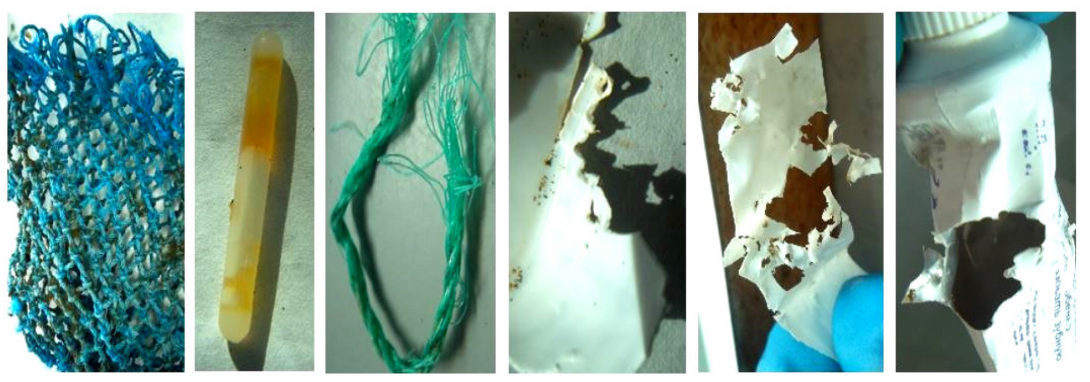

Figure 5: Photographs of examples of fishing-related debris and bite marks.

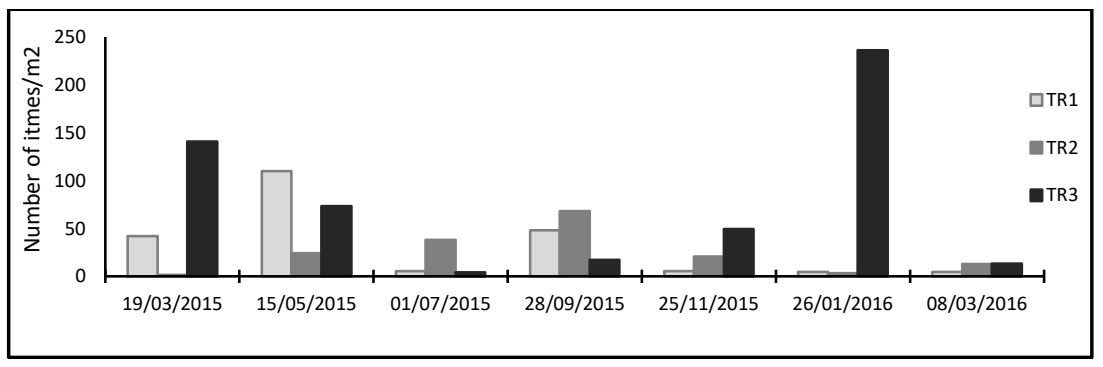

Figure 6: Number of micro- and meso-debris items per square meter for each transect, during the period from March 2015 to March 2016.

collected in TR1 is generally low but reaches values over 50 in some months. However, the number of items observed in TR2 shows a more regular pattern, increasing from March to July, declining until January and experiencing a slight increase in the last survey. In TR3, it decreases from March to July and then increases until reaching a maximum in January for drastically reducing in the last survey. In general, the largest average deposition of items on the beach occurs in January $\left(81\right.$ items $\left./ \mathrm{m}^{2}\right)$ while the lowest stranding takes place during March $2016\left(15\right.$ items $\left./ \mathrm{m}^{2}\right)$. Regarding the specific transects, it is observed in Fig. 7 that TR3 accumulated the higher number of items during the sampling period. In fact, more than half $(58 \%)$ of all items have been collected in this transect, while the total number of items recovered in the other two transects is quite similar, only slightly lower in TR2. The average number of micro and meso-plastic pieces in each of the three transects is, 80.66 items $/ \mathrm{m}^{2}$ in $\mathrm{TR} 3,34$ items $/ \mathrm{m}^{2}$ in TR1, and 28 items $/ \mathrm{m}^{2}$ in TR2. 
It is interesting to remark that the average value of items by transect and its standard deviation are of the same order for the three transects. In particular, mean and standard deviation are almost the same in TR2 while in TR1 and specially in TR3 the standard deviation is larger than the mean. This fact highlights the significant variability in the number of item pertransect observed throughout the year, only slightly lower in TR2. This could be understood asa more constant debris deposition,possibly due to local process (e.g. beach users or proximity of the walkway to the beach) and a lower influence of the marine dynamics.

Regarding the type of materials found per transect, it can be observed (see Fig. 8) that fragments type is the most frequent type of materials found in any transect. Transect TR1 suspiciously receives much more line type (which are basically mono-lines of nylon) than in any other transect. This could be related with main fishing-related activities developed in their inmediate vecinity. In terms of materials size, the range of diameters between 1.4 and

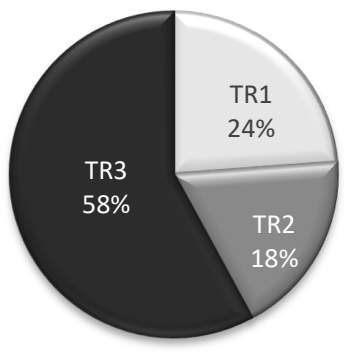

Figure 7: Percentage of items per transect, TR1 (La Puntilla), TR2 (Playa Chica), and TR3 (La Cicer) (03/2015-03/2016).

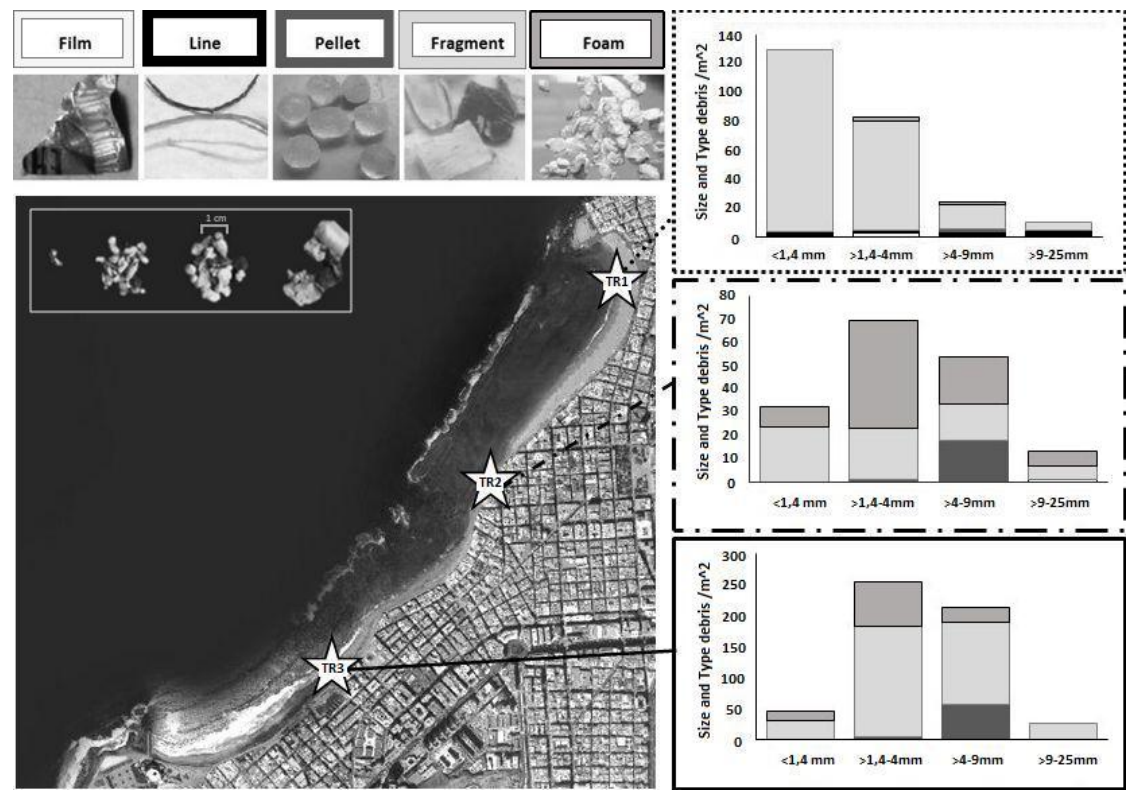

Figure 8: Number of pieces, size and type per $\mathrm{m}^{2}$ for each transect (TR1 (La Puntilla), TR2 (Playa Chica) and TR3 (La Cicer)). 
$4 \mathrm{~mm}$ is predominant in all transects. Nevertheless, TR1 differs from the other two transects by receiving more small size items, while TR2 and TR 3 have similar proportion for this size range. Furthermore, there is a notable gradient of size from TR1 to TR3 where size predomiance goes from smaller to bigger, withhigher amounts of $<1.4 \mathrm{~mm}$ materials at TR1 and higher amounts in the range between $4-9 \mathrm{~mm}$ at TR3.

\subsection{Macro debris}

The analysis of macro-debris items collected in the three transects indicates a higher presence of debris at TR3 (La Cicer), a result similar to that found in the case of micro and mesodebris. However, in this case, it is important to examine this fact through the comparison between different groups of debris. Fig. 9 shows pie charts representing the total amount of debris items (Fig. 9(a)), total synthetic debris (Fig. 9(b)), and cigarette filters (Fig. 9(c)). Considering the total amount of items stranded in each transect (Fig. 9(a)), TR2 would be the most polluted transect. Nevertheless, taking into account only synthetic materials(Fig. 9(b)), TR3 is by far the most polluted transect. This apparently contradictory result is the result of the great presence of cigarette filters at TR2, as observed in Fig. 9(c). The TR2 receives more cigarette filters than the other two transects. This finding suggests a particular type of user on this beach area.

The average and standard deviation values of total macro-debris collected along each transect are: $51 \pm 58$ for TR1, $128 \pm 39$ for TR2, and $91 \pm 48$ for TR3. Thus, in terms of the average number of items per transect, TR2 and TR3 are the areas where more debris is found. The relatively small standard deviation in TR2 indicates the lower variabilityin the number of items encontered at this site, in relation to the other zones of the beach, a fact that could be linked with a more or less continuous pollution due to smoker beach user and/or a lower variability in hydrodynamic conditions.

The main composition of synthetic items per transect is represented in Fig. 10. The graph shows a clear majority of hard plastic items on all the transects, being this synthetic material type the most abundant, followed by plastic films, foamed plastic and rubber.From the hard plastic group, the pieces subgroup constitutes the main type of material found on TR2 and TR3, and plastic nets-ropes for TR1 (62\%) (and only 12\% at TR2 and TR3). As it was mentioned in the classification description, ropes and netsitems are typically used on fishingrelated activities. As a result, TR1 is highly influenced by marine source debris, or at least by fishing related activities.

To address this issue more in depth, items were screened for possible signs of marine source materials, such as bites or biofouling marks, or to be identified as marine related-
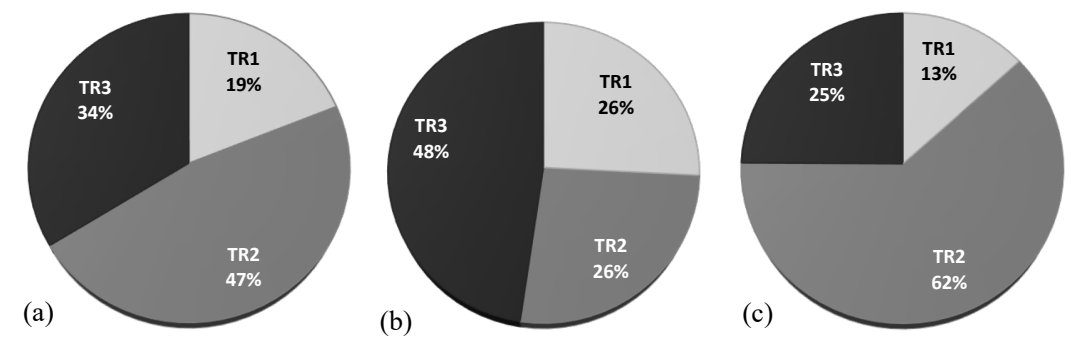

Figure 9: (a) Total debris per transect, (b) total synthetic debris per transect, (c) total cigarette filters per transect. 


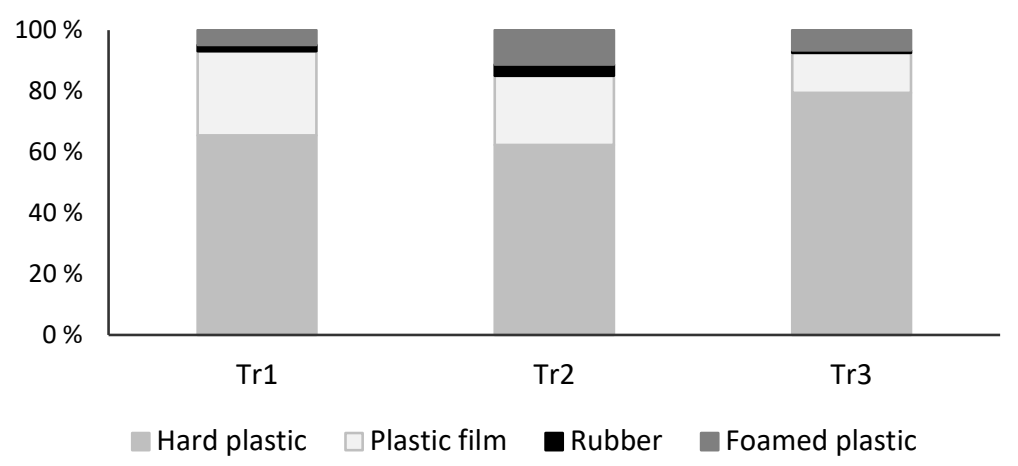

Figure 10: Percentage of synthetic main groups items per transect.

Table 2: Percentage of items stranded on the beach with possible marine source.

\begin{tabular}{|ccc|}
\hline & Total debris (\%) & Synthetic debris (\%) \\
\hline Tr1 & 45 & 58 \\
\hline Tr2 & 34 & 50 \\
\hline Tr3 & 50 & 68 \\
\hline
\end{tabular}

activities materials. Table 2 shows the percentage of itemsper transect for which it has been possible to assign a marine origin. It can be observed that transects located in the northern and southern limits of the beach, TR1 and TR3,presentthe larger percentages of pieces with some of these visible signs. The occurrence of this type of materials is lower at TR2 in both cases, specially when considering the total amount of macro-debris. Again, this indicates a larger influence of debris released by beach users in this zone, which could be relatively easily alleviated through specific procedures and actions aimed at limiting and mitigating its consequences.

\section{CONCLUSIONS}

Regarding micro- and meso-debris, the density of items collected during the most part of the year along the three transects is over 50 items $/ \mathrm{m}^{2}$, so that this kind of pollution is present almost continuously. Furthermore, the density of debris is lower at TR1 (La Puntilla) and TR2 (Playa Chica) and increases toward TR3 (La Cicer), with more than half of the total debris stranded on the beach collected in this last transect, corresponding to the southern end of the beach, significantly exposed to the wave action and which predominant use is beach sports. Nevertheless, a significant variabiliry in the number of items per transect is observed along the three transects but is slightly lower in TR2. The reduction of the standard deviation in the latter could be understood as a more constant debris deposition, possibly due to local process (e.g. beach users or proximity of the walkway to the beach) and/or a lower influence of the marine hydrodynamics. Fragments type is the most frequent type of materials found in any transect, but transect TR1 receives much more nylon lines than any other transect, which is probably linked to the fishing-related activities developed in their inmediate vecinity. In terms of materials size, the range of diameters between 1.4 and $4 \mathrm{~mm}$ is predominant in all transects. 
Macro-debris are more frequent at TR3 (La Cicer) but TR2 receives more cigarette filters than the other two transects jointly, a fact that suggests a particular type of user in this beach area. This hypothesis could also be endorsed by the relatively small standard deviation of the number of items encontered at this site, suggesting a more or less continuous pollution due to smoker beach user. However, it could also be related to a lower variability in hydrodynamic conditions.

Transects located in the northern and southern limits of the beach, TR1 and TR3, present the larger percentage of pieces with visible signs suggesting marine source debris type, or at least materials related to fishing activities. The occurrence of this type of materials is lower at TR2, providing even more evidence of a larger influence of debris released by beach users in this zone.

Conclusions derived from the present study have to be interpreted with caution since the limitation imposed by the one year duration of the observational period. This should be extended over several years to be able to detect stretches of beach and periods during which stranded marine debris amount increases or declines, as well as to identify possible cyclic patterns.

\section{ACKNOWLEDGEMENTS}

Thanks are due to the council of Las Palmas de Gran Canaria for providing information on the activities of the beach clean-up services and to those who collaborate in the field measurement campaigns.

\section{REFERENCES}

[1] Barnes, D.K.A., Galgani, F., Thompson, R. \& Barlaz, M. Accumulation and fragmentation of plastic debris in global environments. Phil. Trans. Royal Society B: Biological Sciences, 364, pp. 1985-1998, 2009.

[2] Vegter, A.C., Barletta, M., Beck, C., Borrero, J., Burton, H., Campbell, M.L., Costa, M.F., Eriksen, M., Eriksson, C., Estrades, A., Gilardi, K.V.K., Hardesty, B.D., Ivar do Sul, J.A., Lavers, J.L., Lazar, B., Lebreton, L., Nichols, W.J., Ribic, C.A., Ryan, P.G., Schuyler, Q.A., Smith, S.D.A., Takada, H., Townsend, K.A., Wabnitz, C.C.C., Wilcox, C., Young, L.C. \& Hamann, M. Global research priorities to mitigate plastic pollution impacts on marine wildlife. Endangered Species Research, 25(3), pp. 225247, 2014.

[3] Blickley, L.C., Currie, J.J. \& Kaufman, G.D. Trends and drivers of debris accumulation on Maui shorelines: Implications for local mitigation strategies. Marine Pollution Bulletin, 105(1), pp. 292-298, 2016.

[4] Somerville, S.E., Miller, K.L. \& Mair, J.M. Assessment of the aesthetic quality of a selection of beaches in the Firth of Forth, Scotland. Marine Pollution Bulletin, 46(9), pp. 1184-1190, 2003.

[5] Thompson, R.C., Moore, C.J., vom Saal, F.S. \& Swan, S.H. Plastics, the environment and human health: current consensus and future trends. Philosophical Transactions of the Royal Society B: Biological Sciences, 364(1526), pp. 2153-2166, 2009.

[6] Derraik, J.G.B. The pollution of the marine environment by plastic debris: a review. Marine Pollution Bulletin, 44, pp. 842-852, 2002.

[7] McDermid, K.J. \& McMullen, T.L. Quantitative analysis of small-plastic debris on beaches in the Hawaiian archipelago. Marine Pollution Bulletin, 48(7-8), pp. 790794, 2004.

[8] Coe, J.M., \& Rogers, D.B. Marine Debris: Sources, Impacts and Solutions. Springer: New York, pp. 432, 1997. 
[9] Moore, C.J. Synthetic polymers in the marine environment: A rapidly increasing, longterm threat. Environmental Research, 108(2), pp. 131-139, 2008.

[10] Ryan, P.G., Moore, C.J., van Franeker, J.A. \& Moloney, C.L. Monitoring the abundance of plastic debris in the marine environment. Philosophical Transactions of the Royal Society B: Biological Sciences, 364(1526), pp. 1999-2012, 2009.

[11] Santos, I.R., Friedrich, A.C. \& Barretto, F.P. Overseas garbage pollution on beaches of northeast Brazil. Marine Pollution Bulletin, 50, pp. 778-786, 2005a.

[12] Santos, I.F., Friedrich, A.C., Wallner-Kersanach, M. \& Fillmann, G. Influence of socio-economic characteristics of beach users on litter generation. Ocean \& Coastal Management, 48, pp. 742-752, 2005b.

[13] Jambeck, J.R., Geyer, R., Wilcox, C., Siegler, T.R., Perryman, M., Andrady, A., Narayan, R. \& Law, K.L. Plastic waste inputs from land into the ocean. Science, 347(6223), pp. 768-771, 2015.

[14] Critchell, K., Grech, A., Schlaefer, J., Andutta, F.P., Lambrechts, J., Wolanski, E. \& Hamann, M. Modelling the fate of marine debris along a complex shoreline: Lessons from the Great Barrier Reef. Estuarine, Coastal and Shelf Science, 167, pp. 414-426, 2015.

[15] Liubartseva, S., Coppini, G., Lecci, R. \& Creti, S. Regional approach to modeling the transport of floating plastic debris in the Adriatic Sea. Marine Pollution Bulletin, 103(1-2), pp. 115-127, 2016.

[16] Rees, G. \& Pond, K. Marine litter monitoring programmes - A review of methods with special reference to national surveys. Marine Pollution Bulletin, 30(2), pp. 103-108, 1995.

[17] Velander, K. \& Mocogni, M. Beach litter sampling strategies: Is there a 'best' method? Marine Pollution Bulletin, 38(12), pp. 1134-1140, 1999.

[18] Martínez, J., Alvarez, R., Alonso, I. \& del Rosario, M.D. Analysis of sedimentary processes on Las Canteras beach (Las Palmas, Spain) for its planning and management. Engineering Geology, 29, pp. 377-386, 1990.

[19] Hidalgo-Ruz, V., Gutow, L., Thompson, R. \& Thiel, M. Microplastics in the marine environment: A review of the methods used for identification and quantification. Environmental Science \& Technology, 46(6), pp. 3060-3075, 2012.

[20] Baztan, J., Carrasco, A., Chouinard, O., Cleaud, M., Gabaldon, J.E., Huck, T., Jaffrès, L., Jorgensen, B., Miguelez, A., Paillard, C. \& Vanderlinden, J.P. Protected areas in the Atlantic facing the hazards of micro-plastic pollution: First diagnosis of three islands in the Canary Current. Marine Pollution Bulletin, 80(1-2), pp. 302-311, 2014.

[21] Carson, H.S., Lamson, M.R., Nakashima, D., Toloumu, D., Hafner, J., Maximenko, N. $\&$ McDermid, K.J. Tracking the sources and sinks of local marine debris in Hawai' $i$. Marine Environmental Research, 84, pp. 76-83, 2013.

[22] Lippiatt, S., Opfer, S., \& Arthur, C. Marine Debris Monitoring and Assessment. NOAA Technical Memorandum NOS-OR\&R-46, 2013.

[23] Ribic, C.A., Sheavly, S.B. \& Klavitter, J. Baseline for beached marine debris on Sand Island, Midway Atoll. Marine Pollution Bulletin, 64(8), pp. 1726-1729, 2012.

[24] Ivar do Sul, J.A., Costa, M.F., Barletta, M. \& Cysneiros, F.J.A. Pelagic microplastics around an archipelago of the Equatorial Atlantic. Marine Pollution Bulletin, 75(1-2), pp. 305-309, 2013. 